\title{
SURROGATE MODEL FOR IMPROVED SIMULATIONS OF SMALL- SCALE SLUDGE INCINERATION PLANTS
}

\author{
Žnidarčič A. *, Seljak T., and Katrašnik T.
}

Faculty of Mechanical Engineering, University of Ljubljana, Aškerčeva 6, SI-1000 Ljubljana, Slovenia

\begin{abstract}
Although various modelling approaches exist for the simulation of solid fuel combustion, no specific model has been developed for the accurate description of gas-phase combustion in small-scale combustion devices. This is particularly limiting in scenarios when volatile-rich, complex and incompletely described solid fuels such as sewage sludge are used. To address this issue, an accurate description of combustion from the fuel bed onwards is required as well as an improved description of emitted volatiles. This paper introduces an innovative surrogate-based combustion model that combines data on sludge devolatilisation and measured combustion characteristics to offer a new surrogate composition. The composition includes heavy hydrocarbon species to accurately describe combustion evolution. A sensitivity analysis revealed that $\mathrm{H}_{2}$ contributes significantly to combustion evolution, while the most robust surrogate composition is obtained when ethanol is used as a leading representative of heavier hydrocarbons. The model can be used to produce suitable surrogates for the main sludge combustion interval, offering the required improvement in fuel descriptions and accuracy of simulations in the vicinity of the fuel bed. Hence, this model is particularly suitable for the optimisation of temperature, heat release rate, and concentration field in combustion chambers with limited volumes.
\end{abstract}

Keywords: sewage sludge, combustion, detailed reaction kinetics, volatiles, fuel surrogates, 3D CFD

*Corresponding author tel.: +386 (0)1 477793

e-mail: anton.znidarcic@fs.uni-lj.si

\section{Introduction}

Waste-to-energy combustion systems are gaining importance with a shift towards circular economies as they enable the cascaded use of materials when recycling is difficult. Meanwhile, combustion-based devices are under negative public opinion due to demands for clean and environmentally sustainable waste processing. An efficient response at the level of local communities is the introduction of small-scale and low-emission combustion systems, as they enable the decrease in environmental effects and feedstock related costs. Such systems process only local waste, emit lower local emissions and decrease transport energy demands. Additionally, increased local selfsustainability regarding heat and power generation is offered. Because of these benefits, small-scale 
combustion systems are becoming important in resolving the problems with processing and disposal of expanding quantities of sewage sludge (SS).

As Ischia [1] and Magdziarz [2] demonstrated, SS includes various harmful components which require stringent processing and disposal control. Current SS treatment methods are aimed at reducing these contaminants; however, Nyakuma [3] indicated that these methods are affected by high cost and low efficiency. Magdziarz [2] and Urych [4] argued that thermal treatment methods are considered to offer the most suitable approach to these challenges, creating an opportunity for the aforementioned systems. Furthermore, note that SS combustion is currently performed primarily in large-scale systems using co-incineration. Hong [5] stated that this is unsuitable from the environmental perspective and, at the same time, it decreases the potential for recovery of valuable ash components. Thus, a viable market for small-scale combustion systems capable of successful SS thermal treatment is emerging and requires the development of such systems.

\begin{tabular}{|c|c|c|c|}
\hline \multicolumn{4}{|c|}{ Nomenclature } \\
\hline SS & sewage sludge & $\mathrm{T}_{\mathrm{i}}$ & temperature at position $\mathrm{i}(\mathrm{K})$ \\
\hline $\mathrm{C}_{\mathrm{i}}$ & species concentration field & $m_{\text {air,i }}^{\prime}$ & air mass flow at position i (kg/s) \\
\hline Cequil. & equilibrium concentration field & $m^{\prime}{ }_{i, j}$ & mass flow of species $\mathrm{j}$ at position $\mathrm{i}(\mathrm{kg} / \mathrm{s})$ \\
\hline $\mathrm{C}_{\text {homog. }}$ & homogeneous concentration field & $h_{\text {air }, \mathrm{i}}$ & specific enthalpy of air at position $\mathrm{i}(\mathrm{J} / \mathrm{kg})$ \\
\hline $\operatorname{Re}$ & Reynolds number & $h_{i, j}$ & specific enthalpy of species $\mathrm{j}$ at position $\mathrm{i}(\mathrm{J} / \mathrm{kg})$ \\
\hline$\Psi$ & combustion propagation velocity & $H H V_{i, j}$ & higher heating value $(\mathrm{J} / \mathrm{kg})$ \\
\hline $\mathrm{HC}$ & hydrocarbon & $P_{\text {rad }}$ & radiative heat transfer (W) \\
\hline
\end{tabular}

With considerable frontloading, the development of combustion systems has become highly dependent on virtual tools. Among these, three-dimensional (3D) computational fluid dynamics (CFD) simulations are of great significance. They aid in achieving fast and affordable optimal designs while providing insight into phenomena that are difficult to characterise. For instance, Costa [6] presented a 3D CFD model of a real-scale refuse-derived fuel (RDF) incineration plant. Mikulčić [7] conducted 
simulations of co-firing coal and biomass in a cement calciner where limestone particles were also traced. Rajh [8] investigated a large waste wood-fired boiler with recycled flue gas using 3D CFD. Later, Rajh [9] advanced their study using air and recycled flue gas staging. Frank [10] demonstrated the capability of 3D CFD simulations in describing nitrous oxide emissions from municipal solid waste (MSW) incineration plants. While all of these studies primarily focused on freeboard conditions, the models presented by Gómez [11] and Ström [12] also described the fuel bed with thermally thick particles. However, despite multiple advances in the area of solid fuel combustion, the above-listed and other studies used noticeable simplifications:

1 Simulations can encompass a wide range of waste-derived fuels; however, they are tailored to larger combustion systems with large freeboard volumes, e.g. Costa [13] discussed waste wood and Lin [14] investigated MSW.

2 Realistic fuels and resulting volatiles are modelled by simplified representations (primarily with syngas components) as indicated in the studies by Murer [15], in which an existing waste-toenergy plant was simulated using the surrogate approach, and Yang [16], in which a specific 1D fuel bed model was applied in simulations of MSW.

3 The models in all the above-mentioned simulations applied simplified chemical kinetics (oneor two-step reactions) in both large- and smaller-scale combustion systems. Example of the latter is work in Gómez [17], describing wood combustion in a small experimental system.

When models with characteristics of the abovementioned simplifications are applied to small-scale systems, limitations imposed by dimensional constraints and highly complex SS compositions noticeably decrease their prediction capability because of the following phenomena:

- Small dimensions lead to lower flow turbulence and weaker flow mixing, resulting in highly heterogeneous flow compositions far above the fuel bed. This fuel-bed-affected region easily extends farther from the secondary air inlets, leading to a heterogeneous combustion process in the freeboard (the schematic representation in comparison with large scale systems is 
shown in Figure 1).

- In addition to high ash and moisture content, $\mathrm{SS}$ is characterised by a high volatile mass fraction which includes numerous volatiles regardless of pretreatment. Data and measurements demonstrating this are given in Calvo [18]. The emission of each volatile depends on the SS temperature, resulting in complex mass loss profiles. Examples of these profiles, provided with thermal gravimetric mass spectrometry (TG-MS) characterisation, can be seen in Nowitzki [19]. Additionally, emitted volatiles exhibit different activation energies and ignition delay times compared with syngas components that are currently used to model combustion in freeboards.

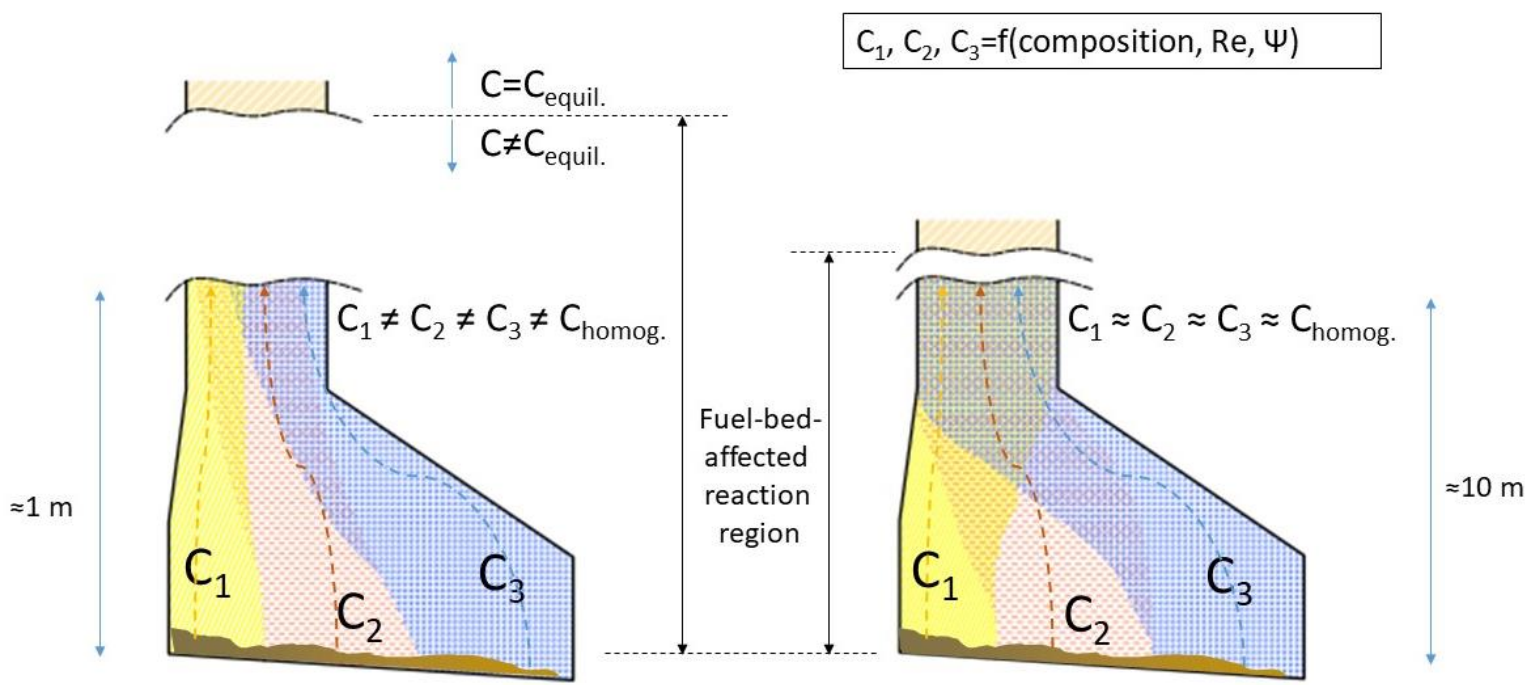

Figure 1. Comparison of small- (left) and large-scale (right) combustion systems in terms of flow homogeneity and species concentrations. Species concentrations are a function of flow composition, Reynolds number and velocity of combustion propagation throughout the fuel-bed-affected region. This region is defined as the volume required for full flow homogenisation.

The combination of scale and composition effects complicates the correct prediction of species concentrations, temperatures, flow field and residence time of combustion products in the fuel-bedaffected region and freeboard of small scale systems. This makes the implementation of Directive 
2010/75/EU [20] difficult (the directive imposes the minimum residence time and temperature of the freeboard).

To present significant progress in this aspect, the main objective of this paper is to improve the description of SS combustion in small-scale systems by developing an innovative fuel surrogate model that can accurately predict concentrations and thermodynamic states throughout the fuel-bedaffected region and at the point of secondary air inlets. This is obtained through the following specific objectives, which also outline the key contributions of this paper:

1. The identification of applicable ranges of new surrogate components that correspond to the devolatilisation data of SS; hence, this includes ethanol, heptane, and propene as the heavy hydrocarbon $(\mathrm{HC})$ representatives.

2. The implementation of detailed reaction kinetics to accurately predict combustion evolution and heat release rates.

3. A comprehensive sensitivity analysis of the developed surrogates in terms of combustion evolution, including the effects of fuel bed temperature, to provide the required flexibility of the model and its applicability to a wide variety of combustion systems.

4. The definition of final surrogate compositions that describe the reactive flow within the fuelbed-affected region. This definition is supported by data obtained through a dedicated experiment.

5. The identification of the optimal surrogates for the SS type used in the study, with the aim to demonstrate the practical applicability of the model.

The above objectives and contributions present an important step towards the accurate prediction of temperatures, concentrations and flow fields in small-scale combustion devices. Although these are considered low-emission devices, they still emit significant concentrations of $\mathrm{SO}_{2}, \mathrm{NO}_{x}$ and particulate matter of different sizes and chemical composition. Thus, the developed model presents also a key 
prerequisite for accurate emission models that enable the appropriate sizing of aftertreatment components, significantly reducing development related costs.

\section{Materials and methods}

This section first presents key SS characteristics, followed by the main considerations and step-bystep procedure of the surrogate model development .

\subsection{Sewage sludge characteristics}

The physical and chemical properties of SS vary considerably with location, processing and environmental and cultural effects. These variations can be observed relatively well through a proximate analysis that indicates high ash, moisture and volatile contents. This is complemented by ultimate analysis data indicating a low carbon and high oxygen content compared with conventional solid fuels, as noted by Magdziarz [2]. The relevant properties of SS are listed in Table 1.

Table 1. Relevant properties of SS as identified in the indicated sources.

\begin{tabular}{lll} 
Variable & Content $[\%$ mass fr.] & Sources \\
\hline Ash & Mostly 20-30, can reach 50 & {$[3,21-27]$} \\
Moisture & Mostly 4-20, can reach 80 & {$[2,3,22,26,28-30]$} \\
Volatiles & Approx. 50, can reach 70 & {$[2,3,22-24,26,28,29]$} \\
Carbon & Mostly approx.30 & {$[2,3,21,26,28,29]$} \\
Oxygen & Mostly approx.20 & {$[2,3,21,26,28,29]$}
\end{tabular}

Fuel thermal decomposition is an important process that must be considered in the development of a combustion model. For conventional solid fuels such as coal or wood biomass, this decomposition and consequential mass loss can be described within a well-defined temperature range. Examples can 
be seen in studies by Magdziarz [2] and Ranzi [31]. On the contrary, SS exhibits a varyingly continuous mass loss from low temperatures onwards. This is accompanied by highly heterogeneous compositions of emitted volatiles that contain several $\mathrm{HCs}$ and organic components, each emitted at its own devolatilisation temperature. However, the decomposition of SS can be crudely divided into three main stages that partially overlap and exhibit multiple emission peaks which overlap as well, as discussed on the basis of thermogravimetric results by Magdziarz [2] and Gao [28]:

- Drying stage. This typically lasts until the $\mathrm{SS}$ attains $400-450 \mathrm{~K}$. Water vapour (moisture), $\mathrm{CO}_{2}$ and simple, light HCs are emitted.

- Main decomposition and mass loss stage. This occurs in the range of 400-850 K. The abundant species that is nearly always detected is $\mathrm{CO}$, accompanied by $\mathrm{H}_{2} \mathrm{O}, \mathrm{CO}_{2}, \mathrm{CH}_{4}$, and $\mathrm{H}_{2}$. Ischia [1] demonstrated that considerable amounts of heavier HCs up to $\mathrm{C}_{9}$ are also detected.

- Final stage. Occurs above $850 \mathrm{~K}$. A minor fraction of sludge mass is emitted during this stage, and the main volatiles are $\mathrm{H}_{2}, \mathrm{CO}$, and $\mathrm{CO}_{2}$.

The focus of the new surrogate model is to accurately describe the main decomposition stage as the majority of mass and energy loss occurs therein. The first step in achieving this is the selection of species to be included in the surrogates. This presents a challenge owing to the numerous and different detected volatiles in various sources in the literature. The following steps were applied to provide a solid basis for the development of the surrogate model:

- Frequently detected components such as $\mathrm{CO}, \mathrm{H}_{2}, \mathrm{CH}_{4}$ and $\mathrm{H}_{2} \mathrm{O}$ are present in all proposed surrogates.

- Three representative $\mathrm{HC}$ candidates were selected to include the presence and effects of different heavier HC components. These are ethanol, propene and heptane.

The heavier $\mathrm{HC}$ representatives were applied in the surrogates separately to limit composition combinations. Propene and heptane were selected after the detection of both saturated and 
unsaturated heavier HCs in the majority of the reviewed literature. Notable examples of these studies are $[1,19,21,27,28,32]$. To provide a detailed analysis with the application of a limited number of heavier HCs, we considered that the longer and shorter HCs would be represented by saturated and unsaturated ones, respectively. On the contrary, ethanol was selected to include the presence of oxygenated compounds. Alcohols are commonly detected in these compounds, with ethanol often being the most prominent, based on data in $[21,27,32]$.

Another challenge in ensuring that the new model can provide an accurate description of combustion is the lack of specific data regarding the fractions of detected volatiles. As noted by Ischia [1] and Conesa [27], measurements provide a limited description of emitted volatiles and, at best, a semi-quantitative analysis of their fractions is achieved. Therefore, the reviewed literature offered only a few studies on the analysis of volume or mass fractions of various volatiles. Table 2 shows mass fraction ranges corresponding to the main decomposition stage obtained from the data in these studies. For simplicity, heavier HCs are combined and their mass fractions are recalculated using ethanol's molar mass.

Table 2. Reported mass fractions of volatiles in the main decomposition stage.

\begin{tabular}{lllllll} 
& $\mathrm{H}_{2}$ & $\mathrm{CO}$ & $\mathrm{CH}_{4}$ & $\mathrm{HCs}$ & $\mathrm{CO}_{2}$ & $\mathrm{H}_{2} \mathrm{O}$ \\
\hline Gao [28] & $0.8-1.33$ & $9-16.5$ & $6.3-10.0$ & $16.2-27.4$ & $50-61$ & $/$ \\
Nowicki [19] & $0.5-5$ & $1.7-58$ & $6.1-24.7$ & $0-3.5$ & $\approx 30$ & $3.7-58$ \\
Karayildirim [32] & $0.2-19.5$ & $31.2-43$ & $1.4-12.7$ & $27-37.9$ & $16.2-28.2$ & $/$
\end{tabular}

As Table 2 shows, considerable variations exist in the mass fractions of the volatiles. Thus, the identified components can be combined in several different ratios to form new fuel surrogates with a range of compositions through which the effects on combustion evolution can be identified. These compositions have to be constrained within realistic values, for which additional data on mass and 
energy balances are required. To ensure this, we provide experimental data on SS combustion in a fuel-bed-affected region with measurements.

\subsection{Experimental measurements}

To develop the new surrogate model, we first obtained validation data on the thermodynamic state and composition of flue gas using a dedicated experiment. The experiment considered a unidirectional laminar flow. Avoiding turbulent flow presence enabled better spatially- and timeresolved measurements of the combustion evolution that appears due to complex fuel characteristics. The experimental setup could gather data in the near-bed region where combustion was not fully completed. This provided a basis for the calibration of the new surrogate model around a transient point as noticeable composition changes are present in this region.

The setup consisted of small, cylindrical (100 mm diameter) fixed-bed laboratory combustion system, supporting a batch combustion of $50 \mathrm{~g}$ of SS in one test operation. It was equipped with primary air preheaters, temperature probes positioned above the fuel bed (Figure 2), pressure sensors to measure pressure drop across grate and bed, and a sampling line to measure the composition of flue gasses $300 \mathrm{~mm}$ from the grate. The test operation consisted of the following steps:

1. The combustion system was preheated to the desired temperature of the primary air (533 K in this scenario) with a mass flow of $8.4 \mathrm{~kg} / \mathrm{h}$.

2. $50 \mathrm{~g}$ of fuel was introduced onto the fixed grate, made from perforated metal with equidistant 2-mm openings (distance between the holes was $2 \mathrm{~mm}$ ).

3. After $30 \mathrm{~s}$ of preheating, the fuel was ignited by introducing $2 \mathrm{~g}$ of burning paraffinic gel.

4. The fuel was let to fully combust while all relevant data was measured.

5. After the main combustion phase, the primary air flow was maintained until the temperature 
of the flue gas equalled that of the primary air.
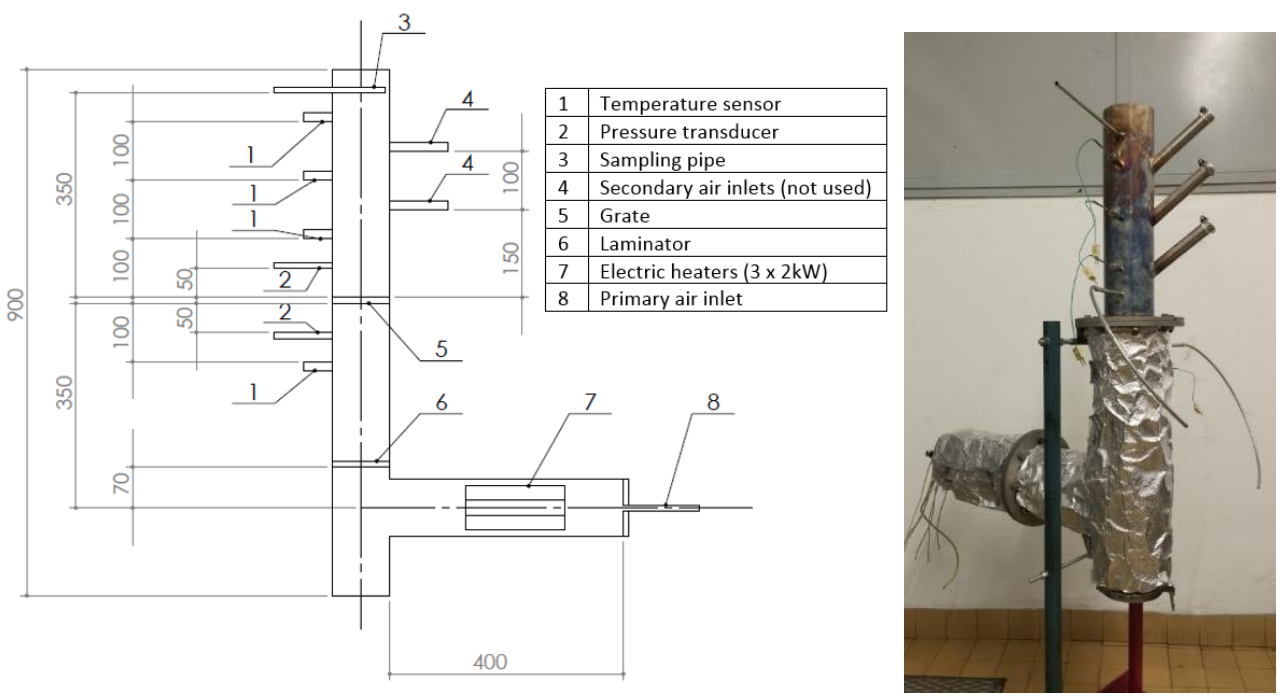

Figure 2. Experimental combustion setup with indicated positions of sensory equipment (full ceramic insulation jacket was removed).

The measurement equipment consisted of shielded K-type thermocouples, a Tecnotest mod. 488 gas analyser with a nondispersive infrared (NDIR) sensor for $\mathrm{HC}$ and $\mathrm{CO}$, and an electrochemical sensor for $\mathrm{NO}$ and $\mathrm{O}_{2}$. Out of several operations, five were selected in which the experimental conditions were stable and representative. Within these operations, the standard deviation of temperature did not exceed $\pm 20 \mathrm{~K}$ and that of $\mathrm{CO}$ measurement did not exceed $0.5 \%$ at any moment. The averaging related smoothing of the data was omitted by selecting the most representative iteration (being the one closest to average) to validate the numerical model. To exclude the possible large amount of residual organic matter and fixed carbon in the ash, we measured the weight loss at $823 \mathrm{~K}$ in an oxidative atmosphere. The range for the selected operations was $6-8 \%$.

The experimental matrix is shown in Table 3 and results from corresponding measurements are shown in Figure 3. The time-resolved data of batch combustion indicated ignition (at approximately 
$250 \mathrm{~s}$ ), the combustion peak interval (at approximately $300 \mathrm{~s}$ ), and the slow oxidation of fixed carbon (from 350 s onwards), which corresponded to the combustion stages identified in Section 2.1. The data clearly indicates that the peak combustion interval exhibited a steady-state period with relatively small changes in temperature and flue gas composition. These data were considered for the development and validation of the new surrogate model as most of the volatiles, including heavier $\mathrm{HCs}$, were emitted during this stage, as discussed in Section 2.1. Table 4 shows the average temperatures and gas compositions within the interval indicated by vertical lines in Figure 3.

The measured flue gas composition was used to identify the fuel formula as $\mathrm{C}_{1} \mathrm{H}_{1.5} \mathrm{O}_{0.22}$. This corresponded with the average SS formula, $\mathrm{C}_{1} \mathrm{H}_{1.8} \mathrm{O}_{0.5}$, identified by gathering and averaging ultimate analysis data from the literature listed in Table 1. The $\mathrm{H} / \mathrm{C}$ ratio in our formula (1.5) is lower than that in the average formula (1.8) because of the characteristics of thermal decomposition. Because of their lower volatilisation temperatures and higher $\mathrm{H} / \mathrm{C}$ ratios, lighter $\mathrm{HCs}$ were first emitted, leading to a decrease in the $\mathrm{H} / \mathrm{C}$ ratio of the remaining solid fuel.

Table 3. Applied parameters in the experimental measurements.

\begin{tabular}{ll} 
Parameter & Value \\
\hline SS batch mass & $50 \mathrm{~g}$ \\
Primer mass & $2 \mathrm{~g}$ \\
Dry matter content & $75 \%$ \\
Preheating phase duration & $90 \mathrm{~s}$ \\
Air temperature & $533 \mathrm{~K}$ \\
Air mass flow & $8.4 \mathrm{~kg} / \mathrm{h}$
\end{tabular}

Table 4. Average values during the steady part of the combustion peak shown in Figure 3.

\begin{tabular}{lllll}
$\mathrm{T}_{4}[\mathrm{~K}]$ & $\mathrm{CO}[\%]$ & $\mathrm{CO}_{2}[\%]$ & $\mathrm{O}_{2}[\%]$ & $\dot{\boldsymbol{m}}_{\text {air }}[\mathrm{kg} / \mathrm{h}]$ \\
\hline 943 & 3.83 & 11.67 & 3.74 & 8.42
\end{tabular}



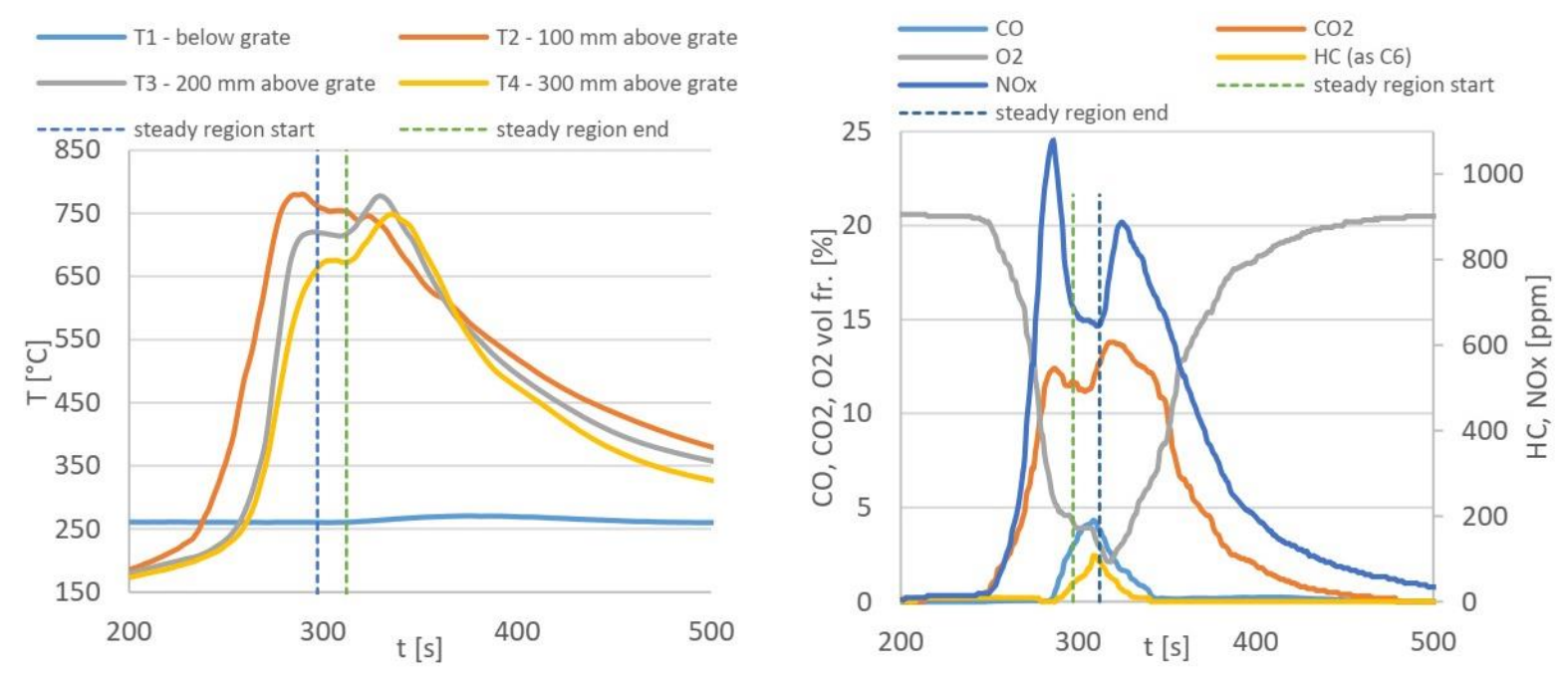

Figure 3. Results from the experimental measurements.

With the obtained experimental data and identified possible surrogate components, all necessary parameters for the development of the new surrogate model were known.

\subsection{New surrogate model for sewage sludge combustion}

The new surrogate model combines the data from our experiment and the literature. Owing to the complexity and variability of SS composition, the model initially proposes the creation of a surrogate composition range. This is not fitted to a single type of SS but follows the general characteristics noted in Table 2 to ensure wider applicability and robustness. In the second step, a specific surrogate composition that best suits the experimentally measured SS combustion is selected through detailed 3D CFD simulations.

Before the model was developed, three assumptions were made according to the observed experimental data. These limited the degrees of freedom but maintained the robustness of the model:

- The fuel bed was assumed to have a constant temperature and mass flow of volatiles. 
- No water evaporation occurred due to the long preheating period and exposure to elevated temperature before the interval observed in the experiments.

- No heat transfer occurred through the walls since they were well insulated, the experimental system was preheated and the experiments relied on periodical batch combustion without furnace cool-down.

An important additional assumption, which significantly improves the universality of the new surrogate model and its application to fuels with high ash contents, is that part of the volatiles emitted from the bed is assumed to react within the bed. This is in accordance with statements made by Yang [16]. The energy released through these reactions is assumed to heat the bed, which presents a considerable sink owing to the high ash fraction in the SS (position 2 in Figure 4). Logically, this leads to the necessity of including flue gas components $\left(\mathrm{CO}_{2}, \mathrm{H}_{2} \mathrm{O}\right)$ in the surrogate (introduced at position 3 in Figure 4), whose quantities correspond to the part of volatiles that react within the bed. By varying the fraction of volatiles that react within or very close to the bed, the effect of different fuel bed temperatures on the selection of suitable surrogates can be evaluated.

The model development comprised the following steps which consider mass and energy balance:

1. Development of the initial surrogate composition range: A surrogate composition range is established with variable fractions of the components identified in Section $2.1\left(\mathrm{H}_{2}, \mathrm{CO}, \mathrm{CH}_{4}, \mathrm{H}_{2} \mathrm{O}\right.$, and $\mathrm{HC}$ candidates). These fractions are defined according to the mass balance. Hence, the initial surrogate composition range is determined in this step.

2. Development of the final surrogate composition range: Based on the established initial surrogate composition range, a fraction of volatiles that react in the fuel bed is determined through an energy balance for different fuel bed temperatures. Consequently, $\mathrm{CO}_{2}$ and $\mathrm{H}_{2} \mathrm{O}$ are included corresponding to the reacted part of the initial surrogate composition. Thus, a final surrogate composition range is obtained. 


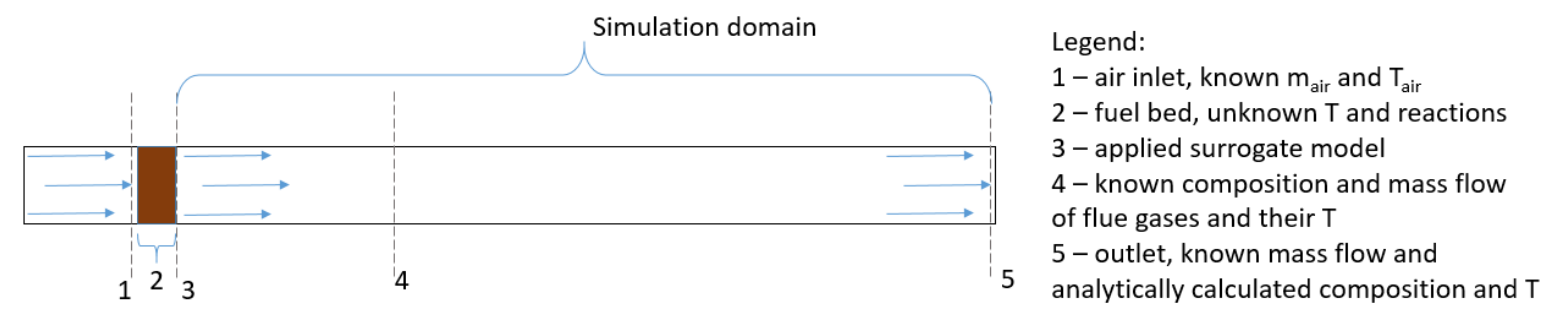

Figure 4. Main positions and data considered in developing the new surrogate model. The region between positions 1 and 4 mimics the experimental system presented in Section 2.2 and includes reactive flow. The region between positions 4 to 5 is included only in the model to attain an equilibrium state and stabilise the simulations.

\subsubsection{Development of the initial surrogate composition range}

The development of the initial surrogate composition range relies on the mass balance criteria and predefined surrogate components. This range is established through a specifically devised computational procedure shown in Figure 5 while considering the fuel formula, identified through experimental and literature data $\left(\mathrm{C}_{1} \mathrm{H}_{1.5} \mathrm{O}_{0.22}\right)$. Initially, the fractions of $\mathrm{CH}_{4}$ and heavy $\mathrm{HC}$ representatives are determined according to their mass fractions reported in studies on devolatilisation. These are shown in Table 2. The results suggest that $\mathrm{CH}_{4}$, while always present, has the most defined range of mass fractions among all the selected components. In all sources, these include values from $0-10 \%$. Heavier HC species exhibit a less predictable range of mass fractions; however, they are less scattered than the ranges of other components. To assess their effect, we defined the mass fraction of the selected heavier $\mathrm{HC}$ representatives in a range similar to that of $\mathrm{CH}_{4}$ (0-10\%). Using the identified fuel formula and mass balance, the presence of other species is determined as a result of $\mathrm{CH}_{4}$ and heavier $\mathrm{HC}$ fractions. This entire procedure is applied using four main steps, which are indicated with arrows in Figure 5 and explained in Table 5. 


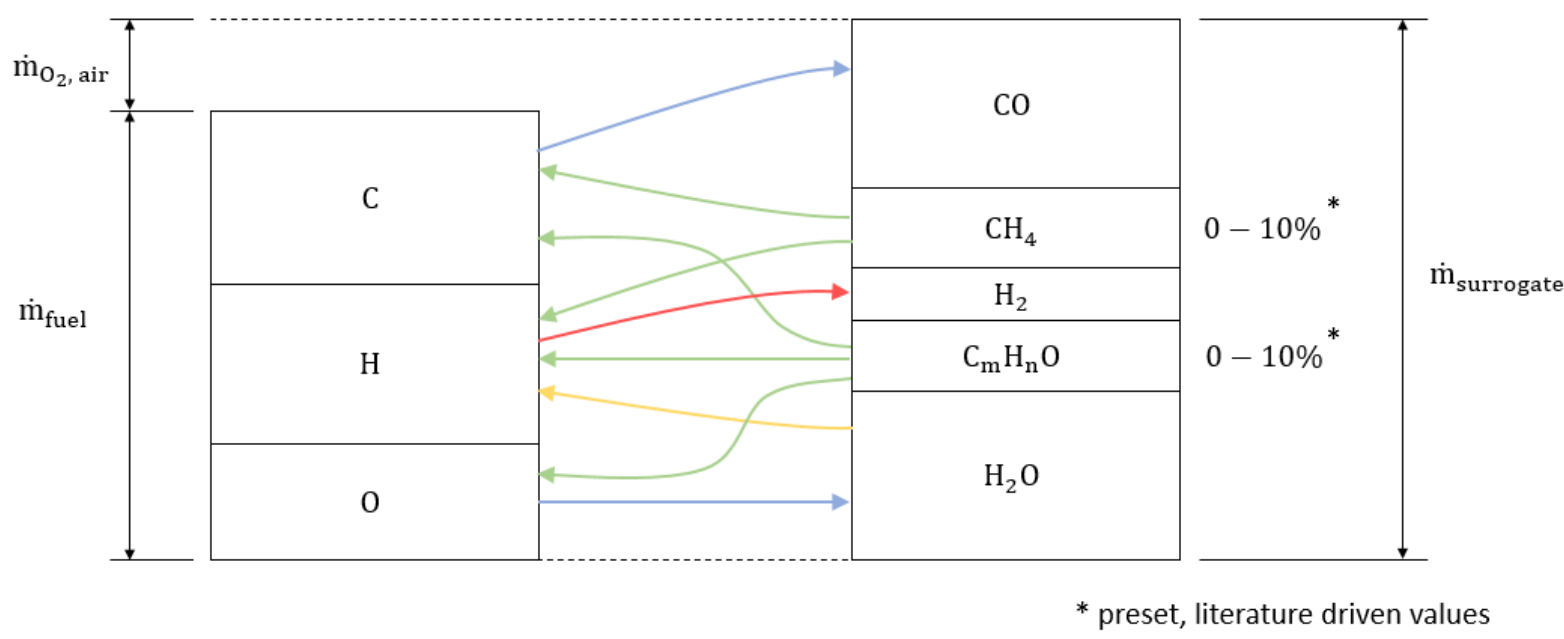

Figure 5. Graphical presentation of the computational procedure devised to define a realistic surrogate composition.

Table 5. Explanation of the four main procedure steps.

\begin{tabular}{lll}
\hline Step & \multicolumn{1}{c}{ Known } & Calculated \\
\hline 1. & Predefined $\mathrm{CH}_{4}$ and $\mathrm{C}_{\mathrm{m}} \mathrm{H}_{\mathrm{n}} \mathrm{O}$ & Required $\mathrm{C}, \mathrm{H}$, and $\mathrm{O}$ mass from fuel \\
& mass fractions in the surrogates & \\
\hline 2. & Remaining $\mathrm{C}$ in fuel & Definition of $\mathrm{CO}$ and $\mathrm{O}$ obtained from air \\
& Remaining $\mathrm{O}$ in fuel & Definition of $\mathrm{H}_{2} \mathrm{O}$ \\
\hline 3. & $\mathrm{H}_{2} \mathrm{O}$ mass in surrogates & Required $\mathrm{H}_{\text {from the fuel }}$ \\
\hline 4. & Remaining $\mathrm{H}$ & Definition of $\mathrm{H}_{2}$ in surrogates
\end{tabular}

As a result, $\mathrm{CO}$ becomes the main combustible gas species, accompanied by a considerable mass fraction of $\mathrm{H}_{2} \mathrm{O}$ and moderate amount of $\mathrm{H}_{2}$. Thus, the identified initial composition ranges resemble the devolatilisation data in Table 2. The procedure facilitates the required flexibility of the model and can be applied to different heavier $\mathrm{HC}$ representatives. Simultaneously, it conserves the $\mathrm{C}, \mathrm{H}$ and $\mathrm{O}$ 
masses by default since it is based on the fuel flow defined with the general fuel formula. The chemical energy of the applied surrogate mixture fits that of dry SS (13-16 MJ/kg).

\subsubsection{Development of the final surrogate composition range}

The final surrogate composition range has to consider the heat released in the bed, through which the effects that different fuel bed temperatures have on the selection of suitable surrogates are also addressed. The energy balance of the entire experimental system is considered. This is given in Eq. (1), which applies measured data from positions 1 and 4 in Figure 4.

$$
\sum_{j} \dot{m}_{4, j} h_{4, j}+\dot{m}_{4, C O} H H V_{C O}-\dot{m}_{a i r, 1} h_{a i r, 1}+\dot{P}_{r a d}=\dot{m}_{2} h_{2}
$$

The first two terms describe the complete energy flow at position 4, composed of the enthalpy of flue gases and chemical energy of unburnt $\mathrm{CO}$. The third term describes energy introduced at position 1 with the combustion air flow. The last term on the left-hand side accounts for radiative heat losses to the surroundings and system caused by combustion in the freeboard. This was defined in simulations to attain values up to $150 \mathrm{~W}$. Hence, the left-hand side of the equation concerns the energy transferred to the gas phase in the system, which is the focus of any surrogate model.

This energy emanates from the fuel bed (position 2) as the chemical energy introduced through the surrogates, described using the term on the right-hand side of Eq. (1). This chemical energy, which is required to satisfy the energy balance, is considered as part of the initial surrogate composition range. The size of this part depends on the fuel bed temperature. This defines the other part that reacts within the bed and is responsible for elevating the fuel bed temperature. This criterion is particularly important when fuels with high ash content are considered. 
The effects of fuel bed temperatures on surrogate selection were considered by comparing three different fuel bed temperatures. For each of them, the part of the initial surrogate composition consumed within the fuel bed was defined. The temperatures are as follows:

- the lowest equals the combustion air temperature used during the experiments (533 K),

- the highest is set by the combustion air temperature at which ash melting occurred (757 K) and presented the upper practical limitation in realistic systems, and

- the third temperature is set as the medium value of the first two (645 K).

Based on the selected bed temperature, the final surrogate composition range is formed. This range is used as an input at position 3, which presents the inflow to the computational domain (fuel bed top). The range features unburnt surrogates, combustion air and flue gases, and is defined through an iterative procedure, which applies Eq. (2). One of the main devolatilisation products from the SS (Table 2), $\mathrm{CO}_{2}$, is by this included in the surrogates as well.

$$
\sum_{j} \dot{m}_{3, j} h_{3, j}=\sum_{i} \dot{m}_{4, i} h_{4, i}+\dot{m}_{4, C O} H H V_{C O}+\dot{P}_{r a d}
$$

\subsection{Numerical setup}

The numerical simulations were performed using a commercial CFD code, AVL Fire [33]. A preliminary analysis of their setup was required to ensure a suitably accurate framework to describe the experimental environment. Importantly, this environment features a simple and small geometry, which involves only the furnace part above the fuel bed with a diameter and length of 0.098 and 2.2 $m$, respectively. Hence, the resulting computational domain, shown in Figure 6, includes a small 
number of hexahedral cells. Laminar flow conditions also contribute to the low cell count and benefit combustion modelling since no turbulence-chemistry interactions are required to be modelled.

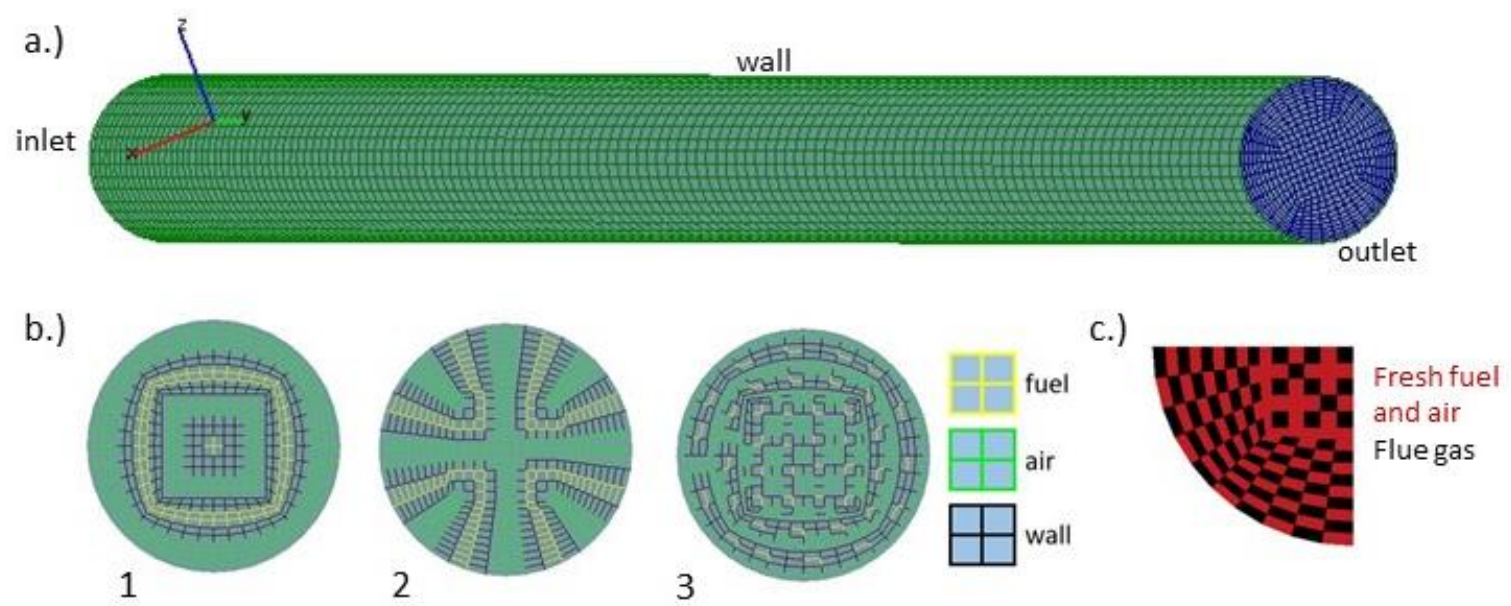

Figure 6. Graphical presentation of applied computational domain: a.) Meshed computational domain with depicted boundaries. b.) Three tested surrogate inlet configurations (1 - circular, 2 - star, 3 dispersed). c.) Final applied surrogate inlet configuration.

The low computational requirements enable the practical application of detailed reaction mechanisms, which use a large number of species transport equations. This is crucial for the complete utilisation of the features of the proposed model as it provides a thorough and valid description of combustion evolution in relation to variations in the surrogate composition. Additionally, a valid sensitivity analysis can be conducted that aims at defining the most suitable surrogate compositions. Three detailed reaction mechanisms were selected, one for each of the proposed heavier HC candidates:

- The mechanism by Olm [34] for the surrogate range with ethanol

- The mechanism by Qin [35] for the surrogate range with propene

- The mechanism by Seiser [36] for the surrogate range with heptane. 
These mechanisms were selected because they provide valid combustion descriptions of the selected heavier HCs in the observed experimental conditions (atmospheric pressure and low to medium temperature).

Table 6 shows the applied numerical methods and schemes, including the model to introduce the detailed mechanisms in simulations, and Table 7 shows the boundary conditions.

Table 6. Used models and schemes

\begin{tabular}{|c|c|}
\hline Governing equations & $\begin{array}{l}\text { Complete set of unsteady compressible Navier-Stokes momentum, continuity, and } \\
\text { energy equations solved via the SIMPLE algorithm } \\
\text { Terms for gravity and pressure work included }\end{array}$ \\
\hline Wall treatment & $\begin{array}{l}\text { No wall functions for the momentum equation } \\
\text { Standard wall function, wall heat transfer }\end{array}$ \\
\hline Applied models & $\begin{array}{l}\text { Internal chemistry interpreter (with multi-zone speed-up option) to include detailed } \\
\text { reaction mechanisms } \\
\text { Discrete transfer radiation model, gas as a participating medium (WSGGM) }\end{array}$ \\
\hline Discretisation schemes & $\begin{array}{l}\text { First-order temporal discretisation }(\Delta \mathrm{t}=0.005 \mathrm{~s}) \\
\text { Blended upwind and central difference schemes for mom. and en. equations } \\
\text { Central difference schemes for the continuity equation } \\
\text { Upwind scheme for scalar transport equations } \\
\text { Least squares fit method to calculate derivatives }\end{array}$ \\
\hline
\end{tabular}

Table 7. Applied boundary conditions.

\begin{tabular}{ll}
\hline Inlet & Variable positions of combustion air and fuel surrogates, with defined composition and \\
& mass flow. Additional wall surfaces, all with pre-defined temperatures \\
& Emissivity factor 1 \\
\hline Wall & No-slip boundary condition \\
& Emissivity factor 0.8 (as estimated for rust iron with a film of carbon deposits) \\
& Adiabatic wall condition imposed with wall thermal resistance of $100 \mathrm{~m}^{2} \mathrm{~K} / \mathrm{W}$ \\
\hline Outlet & Static (atmospheric) pressure of $100 \mathrm{kPa}$ \\
\hline
\end{tabular}

To ensure the proposed numerical setup provides accurate numerical simulations and fully exploits the devised surrogate model, we applied two preliminary analyses:

- surrogate inlet placement and distribution, and

- mesh independence. 
The same combustion conditions were applied in both analyses. They followed the average energy transfer to the gas phase during the entire measured combustion (Figure 3). This resulted in $1.512 \mathrm{~kW}$ of chemical energy and $8.4 \mathrm{~kg} / \mathrm{h}$ of combustion air mass flow introduced into the domain. For the simulations, we assumed an inlet temperature of $473 \mathrm{~K}$, which increased to $893 \mathrm{~K}$ for $1 \mathrm{~s}$ to ignite the mixture (this increase is also applied in simulations with devised surrogate model). An arbitrary surrogate composition was used (Table 8). It featured ethanol as the heavy HC.

Table 8. Surrogate composition applied in preliminary analyses.

\begin{tabular}{cccccc} 
Species & $\mathrm{CO}$ & $\mathrm{C}_{2} \mathrm{H}_{5} \mathrm{OH}$ & $\mathrm{H}_{2}$ & $\mathrm{~N}_{2}$ & $\mathrm{H}_{2} \mathrm{O}$ \\
\hline Mass fraction & 0.316 & 0.13 & 0.043 & 0.32 & 0.191
\end{tabular}

\subsubsection{Surrogate inlet placement and distribution}

Inlet placement study is crucial to defining a suitable numerical setup since the accuracy of the surrogate approach depends on the spatial placement of surrogate inlets, as discussed in a comparison of various inlet placements by Costa [13]. Three different heterogeneous placements and one homogeneous setup were tested (Figure 6).

The dispersed heterogeneous placement of the surrogate inlets was observed to offer the most suitable results. The homogeneous inlets prevented combustion as they imposed very lean conditions, while circular and star inlet patterns led to extremely high local temperatures, which persisted over longer distances. The experimental observations validated the selection of dispersed inlets. This is because the flame shapes indicated the local release of volatiles through channels that were formed in the evenly distributed SS layer on the grate. The morphology and size of the remaining ash, which exhibited a limited volume reduction during combustion, indicated the suitability of applying such inlet placements as well. 


\subsubsection{Mesh independence study}

The inlet placement 1 in Figure 6 (b) was selected for this study owing to its strong heterogeneity, which caused large temperature gradients near the high-temperature zones. Consequently, it made solution quality highly mesh dependent. We observed that mesh independence was satisfied with the mesh depicted in Figure 6 and which was composed of 67,000 elements. The results on this mesh were compared with those from meshes refined with a factor of 1.5 and 2. No considerable differences were observed.

In addition to providing a foundation for the development of the surrogate model, these preliminary tests confirmed that symmetry conditions can be applied. Thus, only a quarter of the geometry was considered in the subsequent simulations, further lowering the number of computational cells and increasing the affordability of using detailed reaction mechanisms. The final inlet setup used in the subsequent simulations is shown in Figure 6 (c).

\section{Results and discussion}

Several simulations were performed to confirm the capabilities of the developed model. We utilised compositions from the devised surrogate ranges in which ethanol, propene and heptane are used as heavier $\mathrm{HC}$ representatives. Therefore, this section first presents these ranges. Subsequently, the surrogate model is evaluated through the following analyses:

- Main surrogate composition effects on the combustion evolution and their effect on the model's applicability to small-scale combustion setups (Section 3.2).

- Mapping and sensitivity analysis of the surrogate composition ranges in relation to their effects 
on the combustion evolution, including the evaluation of the effects of fuel bed temperature (Section 3.3).

- Identification of the optimal surrogate compositions for the SS type used in this study from the group of validated candidates (Section 3.4).

\subsection{Proposed surrogate composition ranges}

The devised surrogate composition ranges are the first results of the proposed model. While it should be acknowledged that the compositions used in simulations follow the energy balance step (Section 2.3.2), it was more practical to evaluate the model considering initial surrogate ranges. This offered a common comparison ground for all simulations.

Figure 7 shows the initial surrogate composition ranges established using the computational procedure shown in Figure 5. They are presented through mass fractions of $\mathrm{CO}, \mathrm{H}_{2} \mathrm{O}$ and $\mathrm{H}_{2}$ in relation to $\mathrm{CH}_{4}$ and heavier $\mathrm{HC}$ mass fractions as these govern the composition definition. By selecting $\mathrm{CH}_{4}$ and the heavy $\mathrm{HC}$ mass fractions on the $x$ and y axes, respectively, the resulting $\mathrm{CO}, \mathrm{H}_{2} \mathrm{O}$, and $\mathrm{H}_{2}$ mass fractions can be identified. The other obtained results are also presented in this manner.

The surrogate ranges in the figure were compared with the data in the literature to estimate whether they are realistic. Since different literature sources reported variable fractions of certain volatiles and acknowledged limited volatile detection abilities, the ranges were not constructed to closely fit all available data. However, the comparison of data in Table 2 with the ranges in Figure 7 indicated that the model provides surrogate ranges with compositions corresponding to different points in the literature:

- The best correspondence is noted for $\mathrm{H}_{2}$ and $\mathrm{CH}_{4}$ mass fractions.

- Heavier $\mathrm{HC}$ candidates and $\mathrm{H}_{2} \mathrm{O}$ correspond to the lower ranges reported in the literature. 
- CO fractions, while being higher, correspond to amplitudes reported in the literature.

Thus, the proposed surrogate ranges were confirmed to provide realistic surrogate compositions. Hence, the computational procedure was confirmed to offer the required flexible and valid definition of surrogate ranges, from which the most suitable compositions are to be defined.
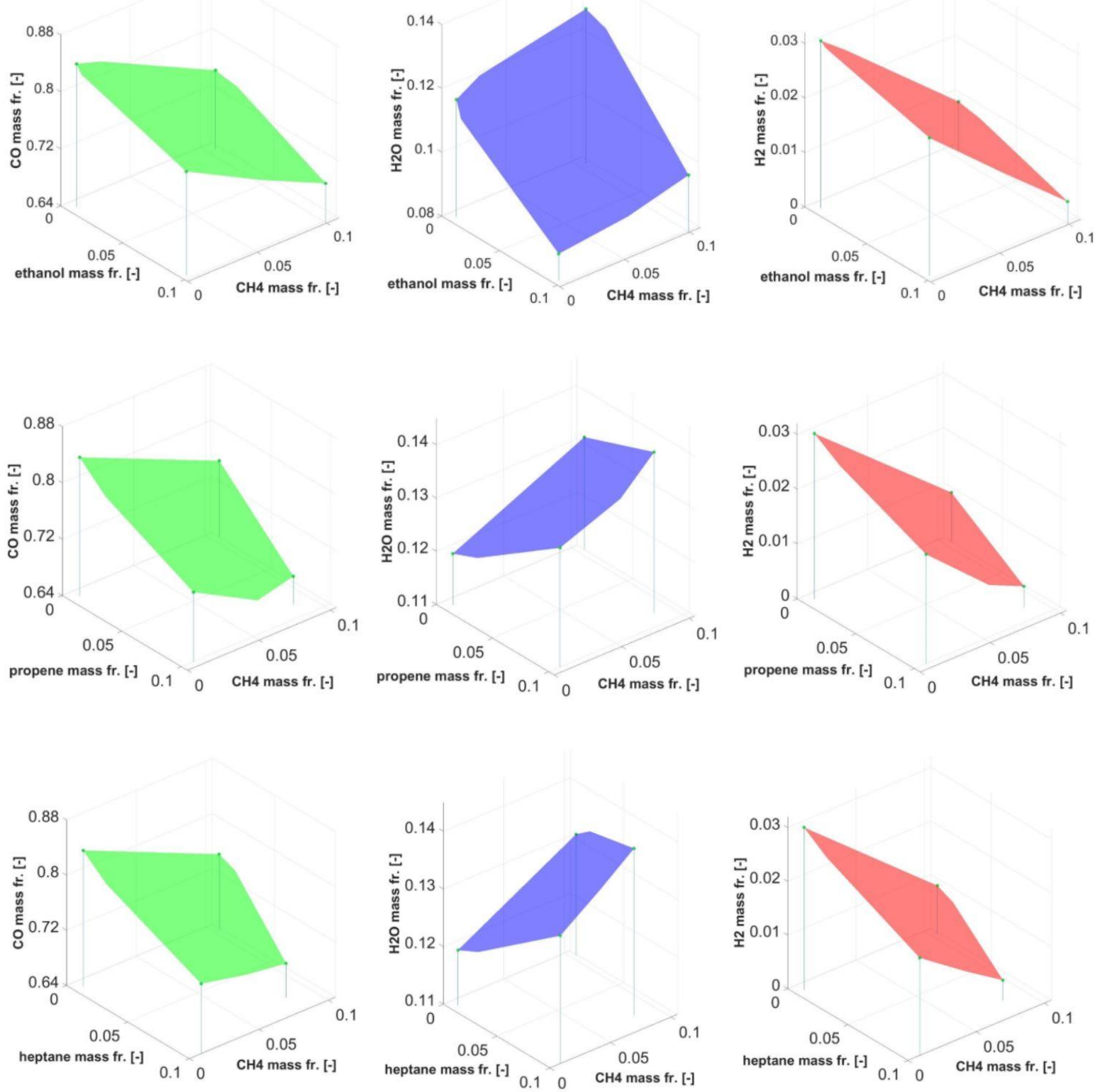

Figure 7. Surrogate composition ranges in relation to methane and heavier $\mathrm{HC}$ mass fractions. The latter are presented by ethanol (top row), propene (middle row) and heptane (bottom). 


\subsection{Surrogate composition effects on combustion evolution}

Simulations with surrogates from the proposed ranges revealed the considerable effects their composition has on combustion evolution. This is particularly important to the ability to obtain an accurate description in the region of combustion systems, in which effects of the fuel bed perform a major function. As discussed in Section 1 (Figure 1), this has an overall effect on the prediction of combustion in small-scale systems. The application of various surrogate compositions resulted in the concept of three main types of combustion evolution:

- Sustained combustion with fast combustion evolution. Nearly all combustion occurs close to the grate, resulting in a rapid increase in temperature and composition homogeneity.

- Sustained combustion with gradual combustion evolution. Combustion proceeds over a longer distance, resulting in lower temperatures and less homogeneous gas compositions near the bed.

- Unsustained combustion, in which combustion gradually extinguishes.

The first two types are shown in Figure 8 with central cross-sections of the temperature fields.

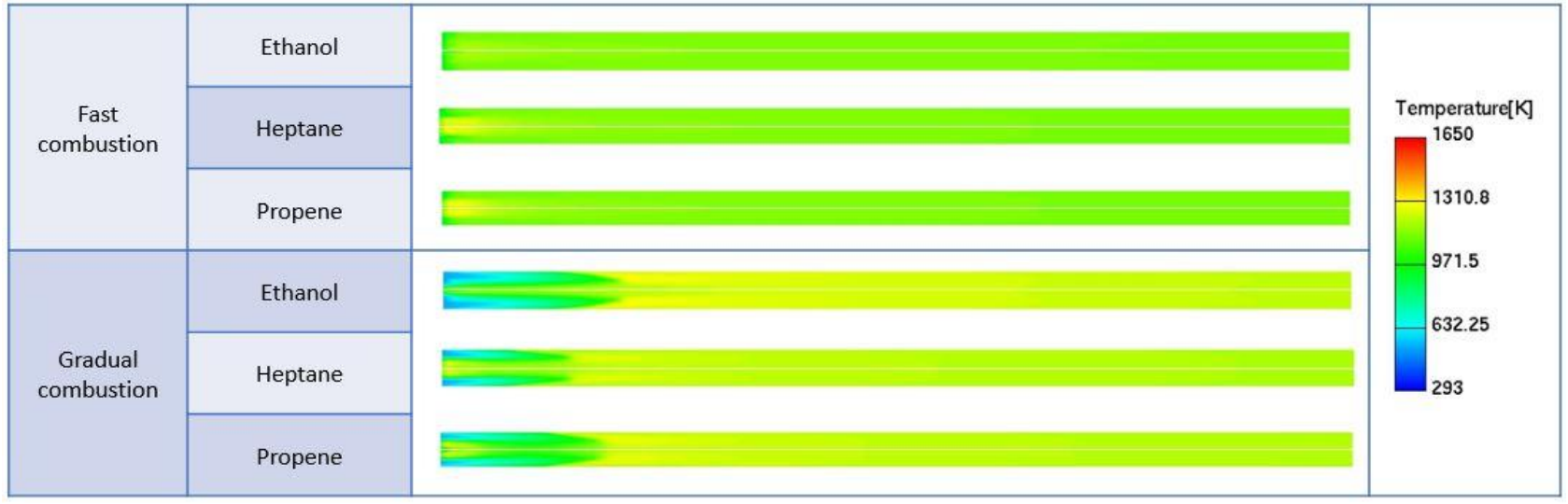

Figure 8. Examples of temperature fields for fast and gradual combustion evolutions for surrogates with each of the heavier $\mathrm{HC}$ representatives. 
Additionally, considerable differences in the results are presented through profiles in the axial and radial directions. An example is shown in Figure 9 with profiles of temperature and $\mathrm{CO}$ mass fraction.
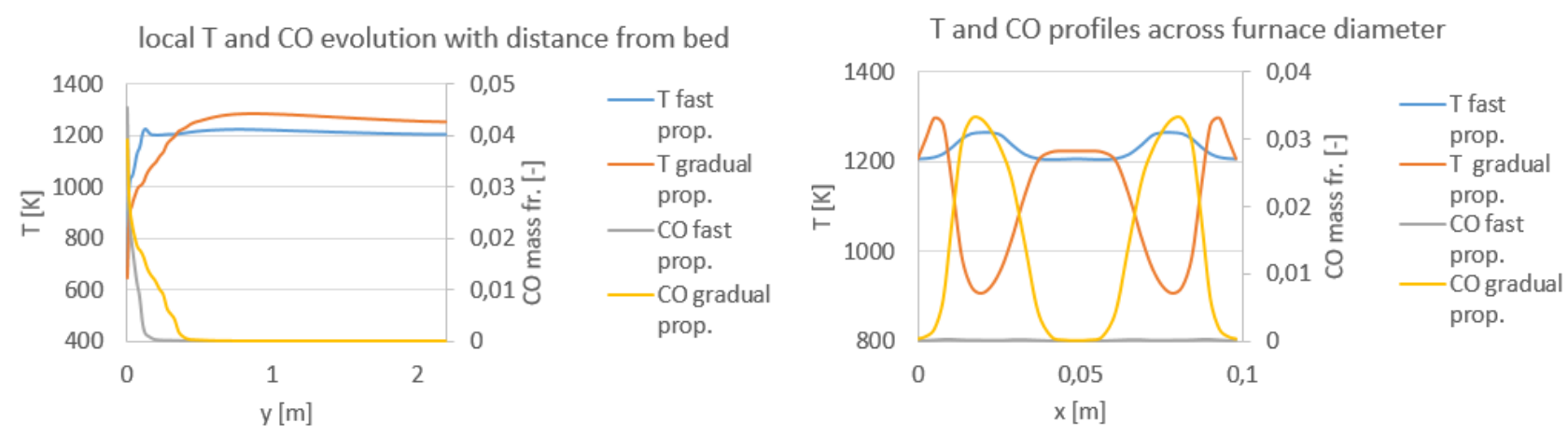

Figure 9. Examples of $\mathrm{T}$ and $\mathrm{CO}$ profiles along the axis (left) and diameter (right) in fast and gradual combustion evolutions. The axial profile lies $12 \mathrm{~mm}$ from the centre while the radial is placed $350 \mathrm{~mm}$ from the grate. The results were obtained for ethanol surrogates for low bed temperature.

Figure 8 and 9 indicate that large differences in temperature and composition fields are observed at positions further than $0.5 \mathrm{~m}$ from the grate. Thus, the combustion process can evolve differently from the bed onwards, depicting the importance of correctly describing it and the surrogate composition that causes it. In addition to the local results, the integral results are affected. Both sustained combustion evolutions exhibit heat release and end temperature, which satisfy analytically defined values with a difference of less than $5 \%$. Thus, the global values imposed on the surrogate model are satisfied. However, the end temperature is for the gradual combustion up to $50 \mathrm{~K}$ higher. This is a consequence of different heat losses through radiation, which, for the gradual combustion, are $100 \mathrm{~W}$ lower than those in the fast one owing to lower local temperatures.

The mapping and analysis of the surrogate responses are required to explain how surrogate composition affects combustion evolution. This is discussed in the next section. 


\subsection{Surrogate response mapping and sensitivity analysis}

The mapping of the surrogate responses was performed together with validation of the results to identify which combustion evolution and its applied surrogates describe the actual conditions in the furnace. In the validation, the numerical results were compared with the measured T and CO mass fractions on the plane on which flue gas composition was measured.

The measurements indicated a considerable amount of $\mathrm{CO}$ and a relatively low temperature on the measuring plane (Table 4). Observing Figures 8 and 9 and considering that the measuring plane was placed $300 \mathrm{~mm}$ from the grate, the measured flue gas composition and temperature indicate that gradual combustion was observed in the experiments. Therefore, the comparison of the experimental and numerical $\mathrm{T}$ and $\mathrm{CO}$ results allows also for identification of the combustion evolution types that certain surrogate compositions provide. Based on this, a sensitivity analysis of the surrogate composition effects on the combustion evolution was conducted. Figure 10 compares the $\mathrm{T}$ and $\mathrm{CO}$ results obtained from the simulations. Results from surrogate ranges with a certain heavy $\mathrm{HC}$ are shown together for all three levels of fuel bed temperature $(533,645$, and $757 \mathrm{~K})$. The $\mathrm{x}$ and $\mathrm{y}$ axes present mass fractions of $\mathrm{CH}_{4}$ and heavy $\mathrm{HC}$ in the initial surrogate ranges, respectively. The experimental values of $\mathrm{T}$ and $\mathrm{CO}$ are depicted with a horizontal plane.

Figure 10 indicates that valid results and experimentally observed combustion conditions could be captured in each of the surrogate ranges. Fuel bed temperature has a slight effect on capturing these conditions. The observed T and CO values in a certain surrogate range exhibit the same trend and very similar values regardless of temperature. The effects of temperature on the results can be summarised as follows:

- The lowest bed temperature leads to the highest observed $\mathrm{T}$ and $\mathrm{CO}$ values in a certain 
surrogate range.

- The experimentally measured flue gas CO mass fraction is achieved only with two lowest bed temperatures.
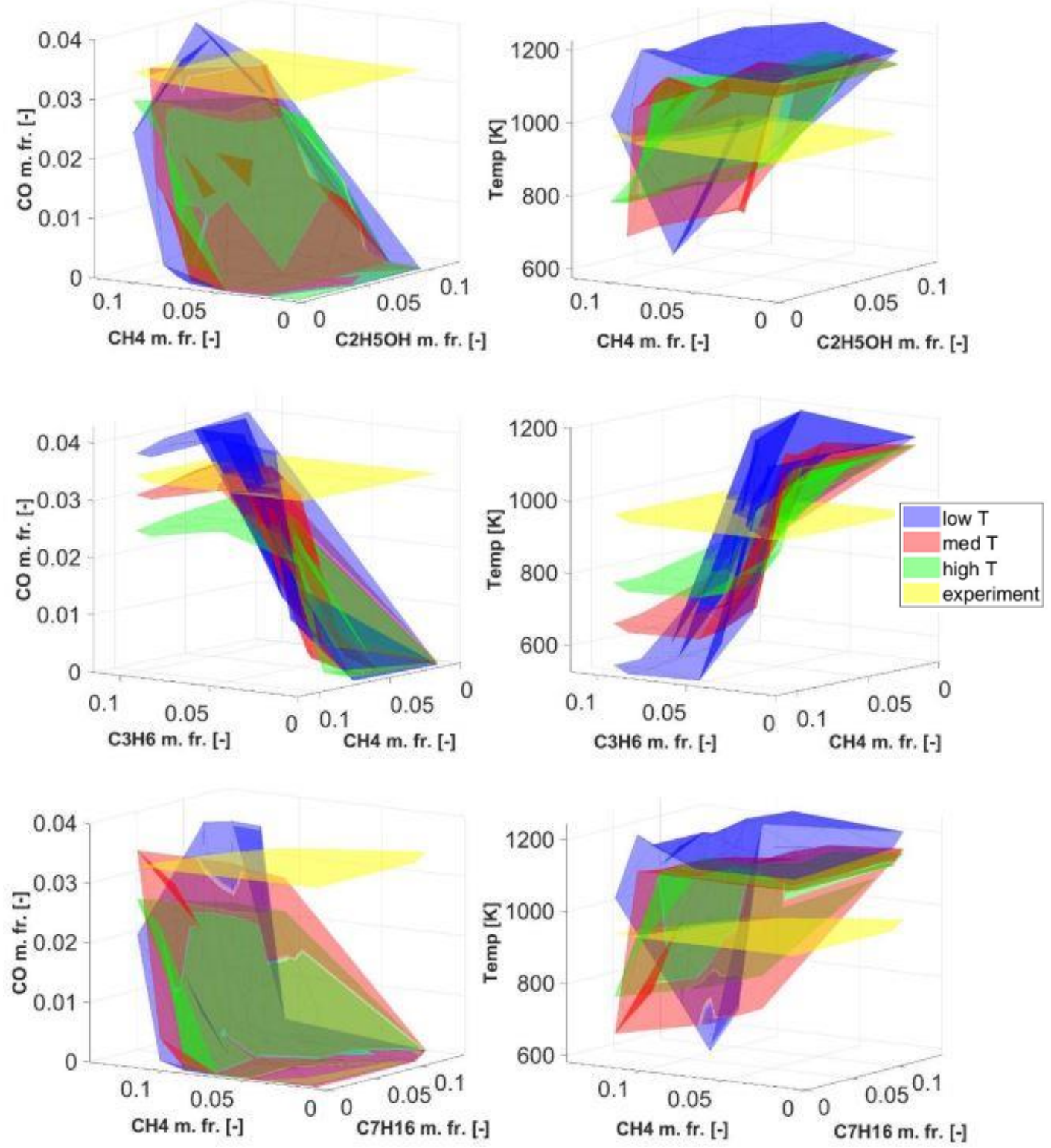

Figure 10. $\mathrm{T}$ and $\mathrm{CO}$ at measuring position for the surrogate ranges including ethanol (top), propene (middle), and heptane (bottom) at all three fuel bed temperatures. Note the different viewpoint for the surrogate range with propene. 
Both effects are consequences of changes in the fraction of unburnt surrogates, introduced into the domain at a certain bed temperature. Contrary to this temperature, surrogate composition can be considered the main factor affecting combustion evolution. To describe the effects of surrogate composition on combustion evolution, we first identified where the three types of combustion evolution, defined in Section 3.2, are present on Figure 10:

- Fast combustion evolution is present in areas with the highest $\mathrm{T}$ and lowest $\mathrm{CO}$ values.

- Unsustained combustion occurs in areas where observed T is below $850 \mathrm{~K}$. The highest CO values accompany these temperatures as another indicator.

- The results corresponding to gradual combustion evolution lie on the sloped part of the plots, between the areas of fast and unsustained combustion.

Sensitivity analysis to define surrogate composition effects on combustion evolution followed the definition of the locations of the combustion evolution types. This analysis was twofold. First, Figure 10 indicates the following:

- The surrogate ranges with ethanol and heptane exhibit similar trends in the T and CO results. Valid results are achieved if the surrogates include higher methane fractions.

- The presence of propene leads to a different dependence of combustion evolution on surrogate composition. Gradual combustion and the most valid results are achieved in a broad range of methane fractions.

- Propene exhibits coupling with methane. The results indicate that the mass fractions of both interchange in positions where valid results are achieved (when one increases, the other decreases, and vice versa).

- Heptane has the narrowest and steepest gradual combustion evolution area, indicating a high sensitivity of combustion evolution towards surrogate composition. 
Thus, the observations indicate that the heavier $\mathrm{HC}$ representatives have a profound effect on the response of a certain surrogate range to combustion. They define where a certain range achieves gradual combustion evolution, which includes valid results for the observed combustion. Thus, we can assume that they affect the reaction velocities or reactivity of surrogates. This was the second considered aspect in the sensitivity analysis to provide a complete description of the governing effects surrogate composition has on combustion evolution. For it, the dependence of reactivity on surrogate composition required description. This followed from the comparison of energy fractions that certain volatiles have in the proposed surrogate ranges. These are independent in relation to the fuel bed temperature. Figures 11-13 show the energy fractions with their values given, as before, in regards to mass fractions of $\mathrm{CH}_{4}$ and the heavier $\mathrm{HC}$ representative. Additionally, the areas of most valid results are depicted on each plot. These are defined as areas where the calculated flue gas temperature is between 900 and $1000 \mathrm{~K}$, thereby closely matching the experimental measurement.

Figures 11-13 indicate that volatiles provide very similar energy fractions in all surrogate ranges. The highest difference is between the heavier HC representatives. Sensitivity analysis to define the effects of composition on reactivity was conducted by comparing the energy fractions of the volatiles in the limiting areas of fast and unsustained combustion evolutions and in the depicted area of most valid results. Table 9 sums its results in the form of the energy fractions of specific volatiles in a certain surrogate range and for a certain observed area. The levels of a volatile's energy fraction are provided relative to its own energy fraction range.

The following conclusions can be derived from Table 9:

- Ethanol and heptane exhibit similarities in energy fractions since they have the same values in different combustion evolution areas.

- $\quad \mathrm{CO}$ and $\mathrm{H}_{2}$ seemingly have similar effects on combustion evolution as their high energy fractions lead to fast combustion evolution while the opposite applies for the lowest values. 
- Propene has a very similar effect on combustion as $\mathrm{CH}_{4}$.

Table 9. Energy fraction levels of different volatiles in observed combustion evolution areas.

\begin{tabular}{ccccc} 
Considered volatile & Surrogate range & Fast comb. evolution & Most valid results & Unsustained comb. \\
\hline \multirow{2}{*}{$\mathrm{CO}$} & Ethanol & high & low & lowest \\
& Propene & high & medium & lowest \\
& Heptane & high & low & lowest \\
\hline \multirow{2}{*}{$\mathrm{CH}_{4}$} & Ethanol & low & high & highest \\
& Propene & entire range & entire range & entire range \\
& Heptane & low & high & highest \\
\hline \multirow{2}{*}{$\mathrm{H}_{2}$} & Ethanol & high & low & lowest \\
& Propene & high & medium & lowest \\
& Heptane & high & low & lowest \\
\hline \multirow{2}{*}{ Heavier HC } & Ethanol & entire range & entire range & entire range \\
& Propene & low & entire range & highest
\end{tabular}
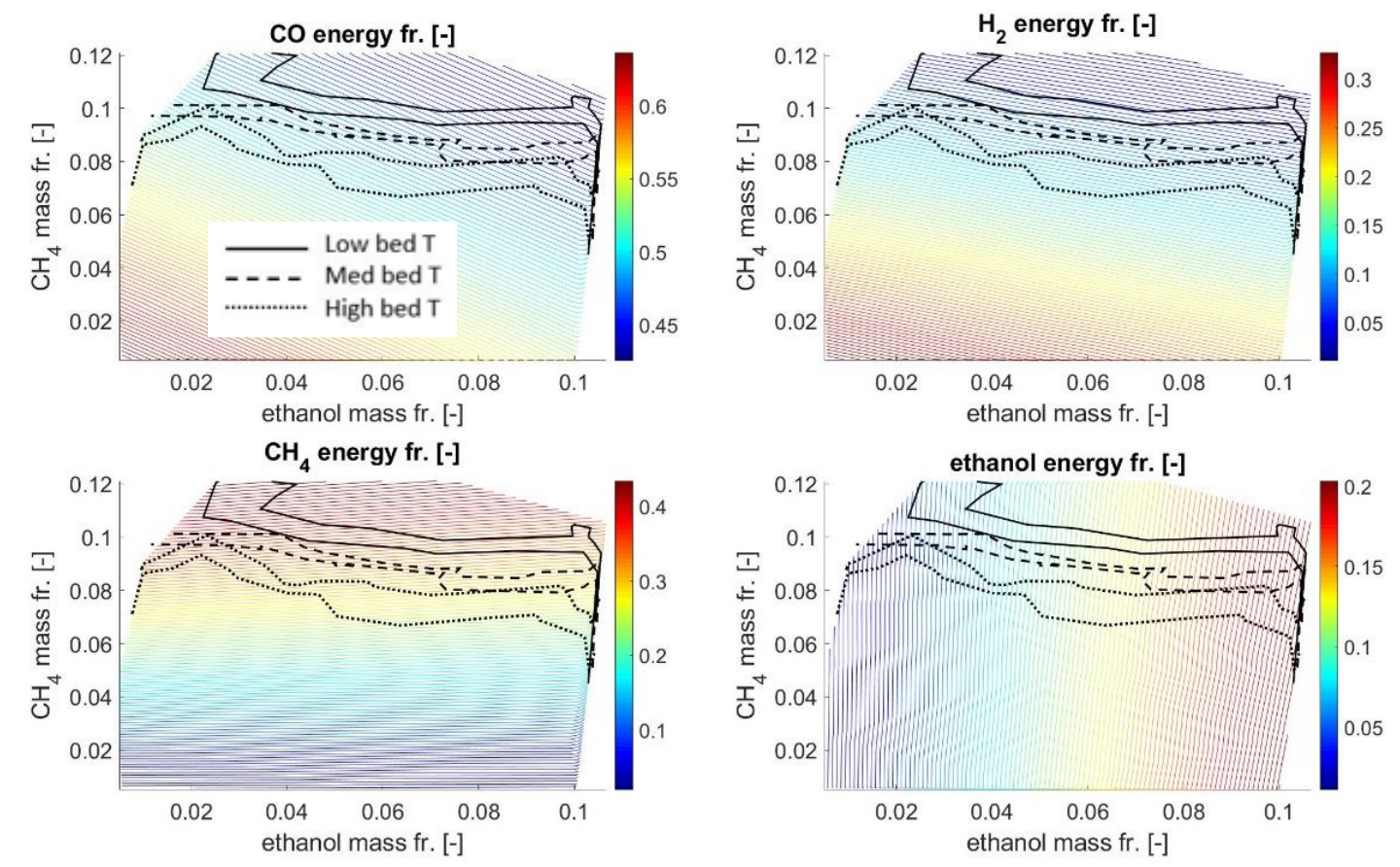

Figure 11. Energy fraction of volatile species in surrogate range with ethanol as the heavy $\mathrm{HC}$ representative. The black lines depict values in the areas of the most valid results. 

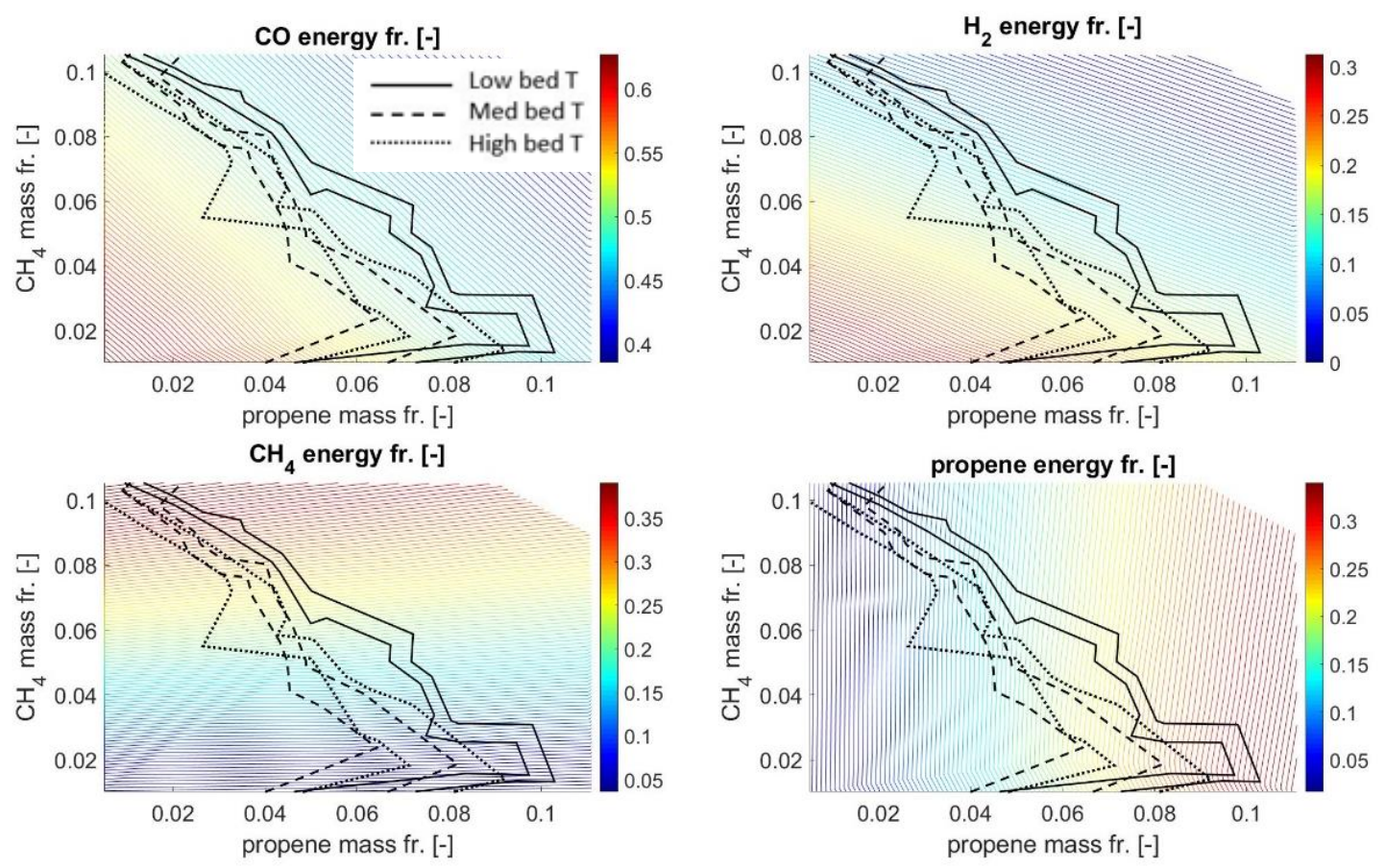

Figure 12. Energy fraction of volatile species in surrogate range with propene as the heavy $\mathrm{HC}$ representative. The black lines depict values in the areas of the most valid results.
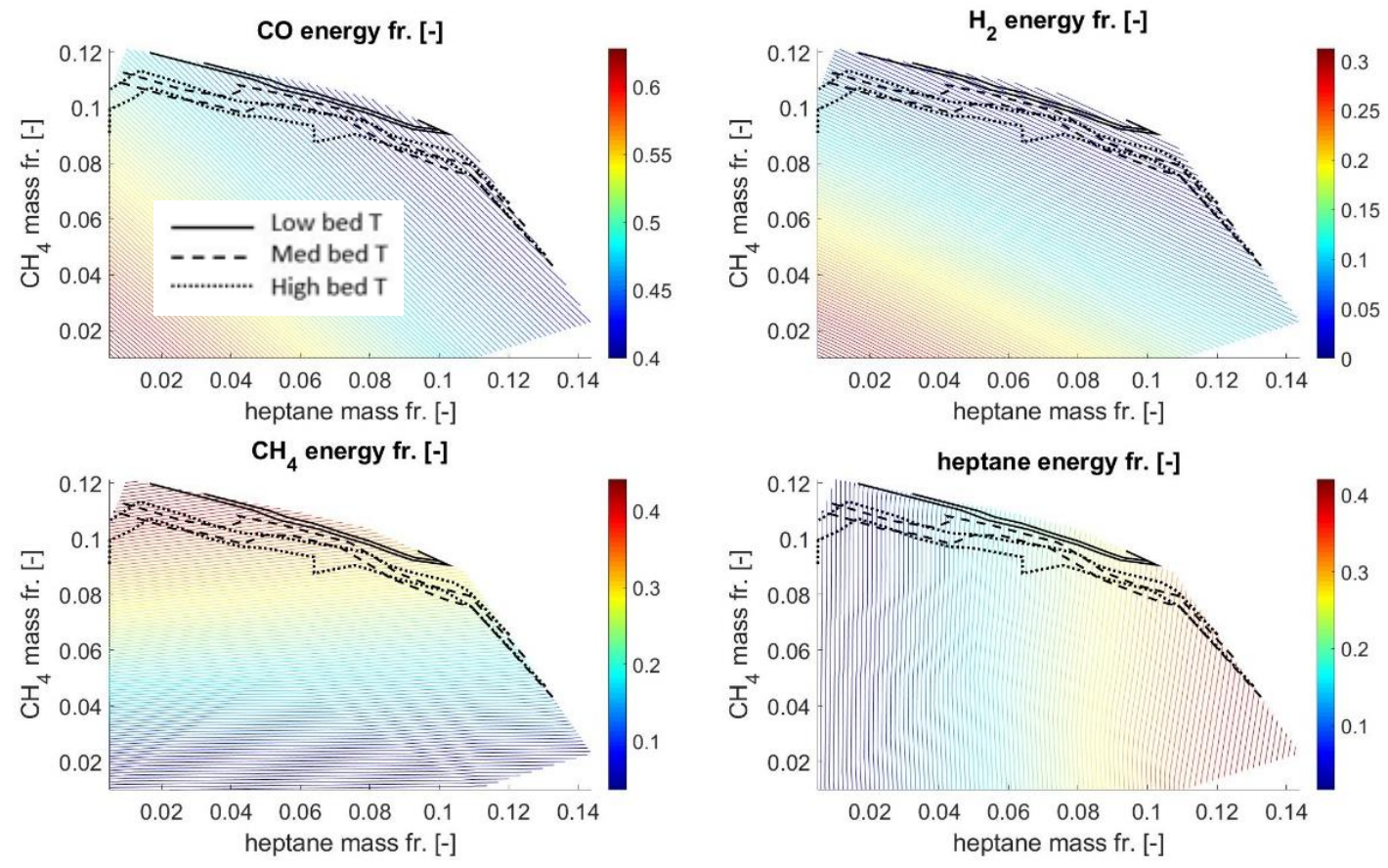

Figure 13. Energy fraction of volatile species in surrogate range with heptane as the heavy $\mathrm{HC}$ representative. The black lines depict values in the areas of the most valid results. 
However, the most important aspect of the results presented in Table 9 is in the definition of the volatile that most affects surrogate reactivity. This was not observed to be a heavy $\mathrm{HC}$ but $\mathrm{H}_{2}$. Its energy fraction is the lowest of all volatiles, yet the combustion evolution changes considerably according to its relative content in the surrogate composition. Additionally, the depicted area of valid results closely follows the direction in which its energy fraction changes. In all surrogate ranges, this area occurs where $\mathrm{H}_{2}$ contributes $5-15 \%$ of the entire surrogate chemical energy. This indicates that the surrogate reactivity is the most sensitive to the energy fraction of $\mathrm{H}_{2}$.

Therefore, the comprehensive sensitivity analysis indicated that the model can capture observed combustion conditions and provide a detailed description of combustion evolution from the fuel bed onwards. The analysis indicated that fuel bed temperature effects are very limited while it crucially enabled the definition which surrogate compositions lead to certain combustion evolutions. In regard to this, the analysis clarified that while the presence of heavier HCs affects surrogate response, the actual cause can be traced to the effects of $\mathrm{H}_{2}$. While this confirmed the previous observation that a valid combustion description can be achieved within all three proposed surrogate ranges, the question of which one provides the most suitable surrogates for the description of observed combustion remains open. This is addressed in the next subsection.

\subsection{Definition of the most suitable surrogate compositions}

The definition of these compositions presents the final and key contribution of the proposed model. The definition considers the model's ability to provide currently missing and experimentally unobtainable valid surrogate compositions through the combination of literature and empirical data using accurate numerical simulations. Two aspects govern this definition:

- The correspondence of the defined surrogate composition with the available literature data.

- The robustness of the surrogate response in relation to achieving valid results. 
The first point concerns whether the surrogate composition relates well to the available literature in different aspects; thus, whether it presents the most realistic possible description. The data from the literature listed in Table 2 were considered for this as they facilitate the estimation of a volatile's mass and energy fractions. The second point ensures that obtaining valid results in simulations does not rely on the application of a very strict definition of surrogate compositions, leading to a very sensitive setup of numerical simulations.

Surrogate compositions with ethanol as the heavy $\mathrm{HC}$ and corresponding to the depicted area of the most valid results were selected as the most suitable for the observed combustion. More strictly, they were defined with ethanol and methane mass fractions between $3-7$ and $7-11 \%$, respectively, and to these corresponding mass fractions of other volatiles (Figure 7).

Considering the first aspect, the compositions with ethanol exhibit good correspondence with the literature data in two regards. In addition to the already stated correspondence in mass fractions (Section 3.1), they importantly correspond well with $\mathrm{H}_{2}$ and $\mathrm{CH}_{4}$ energy fractions. In the defined surrogates, these values are between $5-15 \%$ for $\mathrm{H}_{2}$ and $28-40 \%$ for $\mathrm{CH}_{4}$. This indicates a significantly close match with compositions of the mass fraction ranges shown in Table 2. Energy fractions in ranges of $2-15 \%$ for $\mathrm{H}_{2}$ and $20-40 \%$ for $\mathrm{CH}_{4}$ are observed in these when a translation from mass or volume fractions to energy fractions is applied. Correspondence of the results for $\mathrm{H}_{2}$ is particularly important because of its effect on surrogate reactivity. Note that the same level of correspondence in energy fractions is observed for surrogates with heptane while those with propene include a much wider range of $\mathrm{H}_{2}$ and $\mathrm{CH}_{4}$ energy fractions in their areas of valid results. Consequently, surrogates with propene were not selected as the most suitable. The reason surrogates with heptane were then discarded in favour of the defined ones with ethanol lies in the second aspect. Heptane surrogates clearly exhibit a very narrow area of the most suitable results, revealing too high a sensitivity of simulations in relation to surrogate composition. 


\section{Conclusions}

The paper presents a novel surrogate-based combustion model to properly address combustion aspects in small-scale systems when complex fuels such as SS are used. The key contributions and capabilities of the developed model can be condensed as follows:

- The realistic ranges of surrogates that are suitable for SS based on comparison to devolatilisation data were identified. In addition to common volatiles, the proposed ranges include ethanol, propene and heptane as the heavier $\mathrm{HC}$ representatives. These surrogates provide a more detailed description of fuel thermal decomposition and a basis for the improved description of ignition and combustion in the gas phase.

- The effects that volatiles in surrogate ranges have on ignition and combustion were identified with enhanced reaction kinetics through detailed reaction mechanisms. Affordable simulations using them were ensured with the creation of a specific numerical setup based on a dedicated experimental setup.

- The key parameters which govern combustion evolution were identified through a comprehensive sensitivity analysis.

The sensitivity analysis of different combinations of species within the surrogates revealed the following:

- The model captures different types of combustion evolution (fast, gradual, and unsustained), depending on the surrogate composition used.

- Fuel bed temperature has very limited effects on combustion evolution.

- The presence of $\mathrm{H}_{2}$ in certain surrogate compositions has the largest effect on combustion evolution. Valid results for the experimentally observed combustion are ensured when $\mathrm{H}_{2}$ energy fraction in surrogates achieves $5-15 \%$ of total surrogate chemical energy.

- The optimal surrogate compositions for the experimentally observed SS combustion in this 
study were identified to contain ethanol as the heavy HC representative, with ethanol and methane mass fractions between $3-7$ and $7-11 \%$, respectively.

The analyses herein provide a fully described and validated surrogate model with fully mapped responses of realistic surrogate compositions. This leads to the definition of suitable surrogates and a database for complex and insufficiently described fuels such as SS. Through this, the model presents a considerable increase in the accuracy of modelling SS combustion. Thus, it provides a method for improved 3D CFD combustion simulations, required for the valid and efficient design of innovative small-scale systems. With these, a solution to the increasing demand for environmentally sustainable treatment of SS featuring decentralised incineration capabilities can be provided.

\section{ACKNOWLEDGEMENTS}

The authors acknowledge the support of COST Action CM 1404 - Chemistry of Smart Energy Carriers and Technologies (SMARTCATs), financial support from the Slovenian Research Agency (research core funding No. P2-0401: Energy engineering, and project funding No. Z2-1862: Zero footprint combustion for green energy generation) and the Ministry of Education, Science and Sport through the programme CelCycle. 


\section{References}

[1] Ischia M, Perazzolli C, Dal Maschio R, Campostrini R. Pyrolysis study of sewage sludge by TG-MS and TG-GC-MS coupled analyses. J Therm Anal Calorim 2007;87:567-74. doi:10.1007/s10973006-7690-3.

[2] Magdziarz A, Werle S. Analysis of the combustion and pyrolysis of dried sewage sludge by TGA and MS. Waste Manag 2014;34:174-9. doi:10.1016/j.wasman.2013.10.033.

[3] Bemgba Bevan Nyakuma, Magdziarz A, Werle S. Physicochemical, Thermal and Kinetic Analysis of Sewage Sludge. Proc ECOpole 2016;10:473-80. doi:10.2429/proc.2016.10(1)049.

[4] Urych B, Smoliński A. Kinetics of Sewage Sludge Pyrolysis and Air Gasification of Its Chars. Energy and Fuels 2016;30:4869-78. doi:10.1021/acs.energyfuels.6b00332.

[5] Hong J, Xu C, Hong J, Tan X, Chen W. Life cycle assessment of sewage sludge co-incineration in a coal-based power station. Waste Manag 2013;33:1843-52. doi:10.1016/J.WASMAN.2013.05.007.

[6] Costa M, Massarotti N, Mauro A, Arpino F, Rocco V. CFD modelling of a RDF incineration plant. Appl Therm Eng 2016;101:710-9. doi:10.1016/j.applthermaleng.2016.01.073.

[7] Mikulčić H, Von Berg E, Vujanović M, Duić N. Numerical study of co-firing pulverized coal and biomass inside a cement calciner. Waste Manag Res 2014;32:661-9. doi:10.1177/0734242X14538309.

[8] Rajh B, Yin C, Samec N, Hriberšek M, Zadravec M. Advanced modelling and testing of a 13 MWth waste wood-fired grate boiler with recycled flue gas. Energy Convers Manag 2016;125:230-41. doi:10.1016/j.enconman.2016.02.036.

[9] Rajh B, Yin C, Samec N, Hriberšek M, Kokalj F, Zadravec M. Advanced CFD modelling of air and recycled flue gas staging in a waste wood-fired grate boiler for higher combustion efficiency and greater environmental benefits. J Environ Manage 2018;218:200-8. doi:10.1016/j.jenvman.2018.04.030. 
[10] Frank A, Castaldi MJ. CFD analysis of municipal solid waste combustion using detailed chemical kinetic modelling. Waste Manag Res 2014;32:745-54. doi:10.1177/0734242X14538305.

[11] Gómez MA, Porteiro J, Patiño D, Míguez JL. Fast-solving thermally thick model of biomass particles embedded in a CFD code for the simulation of fixed-bed burners. Energy Convers Manag 2015;105:30-44. doi:10.1016/j.enconman.2015.07.059.

[12] Ström H, Thunman H. CFD simulations of biofuel bed conversion: A submodel for the drying and devolatilization of thermally thick wood particles. Combust Flame 2013;160:417-31. doi:10.1016/j.combustflame.2012.10.005.

[13] Costa M, Massarotti N, Indrizzi V, Rajh B, Yin C, Samec N. Engineering bed models for solid fuel conversion process in grate-fired boilers. Energy 2014;77:244-53. doi:10.1016/j.energy.2014.07.067.

[14] Lin H, Ma X. Simulation of co-incineration of sewage sludge with municipal solid waste in a grate furnace incinerator. Waste Manag 2012;32:561-7. doi:10.1016/J.WASMAN.2011.10.032.

[15] Murer MJ, Spliethoff H, Waal CMW de, Wilpshaar S, Berkhout B, Berlo MAJ van, et al. High efficient waste-to-energy in Amsterdam: getting ready for the next steps. Waste Manag Res 2011;29:S20-9. doi:10.1177/0734242X11413334.

[16] Yang YB, Goh YR, Zakaria R, Nasserzadeh V, Swithenbank J. Mathematical modelling of MSW incineration on a travelling bed. Waste Manag 2002;22:369-80. doi:10.1016/S0956053X(02)00019-3.

[17] Gómez MA, Porteiro J, Patiño D, Míguez JL. CFD modelling of thermal conversion and packed bed compaction in biomass combustion. Fuel 2014;117:716-32. doi:10.1016/j.fuel.2013.08.078.

[18] Calvo LF, Sánchez ME, Morán A, García AI. TG-MS as a technique for a better monitoring of the pyrolysis, gasification and combustion of two kinds of sewage sludge. J Therm Anal Calorim 2004;78:587-98. doi:10.1023/b:jtan.0000046121.14253.38. 
[19] Nowicki L, Ledakowicz S. Comprehensive characterization of thermal decomposition of sewage sludge by TG-MS. J Anal Appl Pyrolysis 2014;110:220-8. doi:10.1016/j.jaap.2014.09.004.

[20] European Council. DIRECTIVE 2010/75/EU OF THE EUROPEAN PARLIAMENT AND OF THE COUNCIL of 24 November 2010 on industrial emissions (integrated pollution prevention and control). vol. L334. 2010. doi:10.3000/17252555.L_2010.334.eng.

[21] Thipkhunthod P, Meeyoo V, Rangsunvigit P, Kitiyanan B, Siemanond K, Rirksomboon T. Pyrolytic characteristics of sewage sludge. Chemosphere 2006;64:955-62. doi:10.1016/j.chemosphere.2006.01.002.

[22] Yao H, Naruse I. Combustion characteristics of dried sewage sludge and control of trace-metal emission. Energy and Fuels 2005;19:2298-303. doi:10.1021/ef0501039.

[23] Calvo LF, Sánchez ME, Morán A, García Al. TG-MS as a technique for a better monitoring of the pyrolysis, gasification and combustion of two kinds of sewage sludge. J Therm Anal Calorim 2004;78:587-98. doi:10.1023/b:jtan.0000046121.14253.38.

[24] Ninomiya Y, Zhang L, Sakano T, Kanaoka C, Masui M. Transformation of mineral and emission of particulate matters during co-combustion of coal with sewage sludge. Fuel 2004;83:751-64. doi:10.1016/j.fuel.2003.09.022.

[25] Zhang L, Ito M, Sato A, Ninomiya Y, Sakano T, Kanaoka C, et al. Combustibility of dried sewage sludge and its mineral transformation at different oxygen content in drop tube furnace. Fuel Process Technol 2004;85:983-1011. doi:10.1016/j.fuproc.2003.10.021.

[26] Shao J, Yan R, Chen H, Wang B, Lee DH, Liang DT. Pyrolysis Characteristics and Kinetics of Sewage Sludge by Thermogravimetry Fourier Transform Infrared Analysis ${ }^{\dagger}$. Energy \& Fuels 2008;22:38-45. doi:10.1021/ef700287p.

[27] Conesa JA, Marcilla A, Moral R, Moreno-Caselles J, Perez-Espinosa A. Evolution of gases in the primary pyrolysis of different sewage sludges. Thermochim Acta 1998;313:63-73. doi:10.1016/S0040-6031(97)00474-7. 
[28] Gao N, Li J, Qi B, Li A, Duan Y, Wang Z. Thermal analysis and products distribution of dried sewage sludge pyrolysis. J Anal Appl Pyrolysis 2014;105:43-8. doi:10.1016/j.jaap.2013.10.002.

[29] Urych B, Smoliński A. Kinetics of Sewage Sludge Pyrolysis and Air Gasification of Its Chars. Energy \& Fuels 2016;30:4869-78. doi:10.1021/acs.energyfuels.6b00332.

[30] Huang Q, Yu B, Qiu K, Zhou G, Wang S, Chi Y, et al. Effect of moisture on sewage sludge combustion temperature profile and heavy metal leaching. Dry Technol 2016;34:1810-9. doi:10.1080/07373937.2016.1142451.

[31] Ranzi E, Cuoci A, Faravelli T, Frassoldati A, Migliavacca G, Pierucci S. Chemical Kinetics of Biomass Pyrolysis Supplementary Information 2008;4:1-5.

[32] Karayildirim T, Yanik J, Yuksel M, Bockhorn H. Characterisation of products from pyrolysis of waste sludges. Fuel 2006;85:1498-508. doi:10.1016/j.fuel.2005.12.002.

[33] AVL. AVL FIRE ${ }^{\text {TM }}$ - avl.com 2018. https://www.avl.com/fire (accessed June 18, 2019).

[34] Olm C, Varga T, Valkó É, Hartl S, Hasse C, Turányi T. Development of an Ethanol Combustion Mechanism Based on a Hierarchical Optimization Approach. Int J Chem Kinet 2016;48:423-41. doi:10.1002/kin.20998.

[35] Qin Z, Lissianski V V., Yang H, Gardiner WC, Davis SG, Wang H. Combustion chemistry of propane: A case study of detailed reaction mechanism optimization. Proc Combust Inst 2000;28:1663-9. doi:10.1016/S0082-0784(00)80565-2.

[36] Seiser R, Pitsch H, Seshadri K, Pitz WJ, Gurran HJ. Extinction and autoignition of n-heptane in counterflow configuration. Proc Combust Inst 2000;28:2029-37. doi:10.1016/S00820784(00)80610-4. 